\title{
CIDADANIA, EDUCAÇÃO E RESPONSABILIDADE SOCIAL: PERCURSOS BIOGRÁFICOS DE JOVENS GRÁVIDAS EM CONTEXTOS DE PROTECÇÃO SOCIAL
}

\author{
LAURA FONSECA ${ }^{*}$ \\ SOFIA SANTOS** \\ José Manuel Peixoto CALDAS * $^{* * *}$
}

\begin{abstract}
RESUMO: Sexualidade, gravidez e parentalidade jovem são assuntos complexos e de grande debate na modernidade tardia globalizada, jogando questões de liberdade e direitos, a par de regulação e controle social público, constituindo-se, assim, em campo de relevância educacional. Este texto revela conhecimento baseado em narrativas de uma jovem portuguesa e outra romena, de 17 e 19 anos, residentes em instituições de protecção social, devido a gravidez e maternidade jovem. Interpretam-se os seus discursos e subjectividades referentes a vivências antes e durante o período de custódia, mas projectando-se além deles. A discussão é enquadrada por relações entre cidadania sexual e íntima e educação, em cada percurso, sem esquecer as regularidades sociais que atravessam as suas vidas e das suas crianças. Discutem-se manifestações e regularidades que relacionam tanto género como poder: desconexão escolar prévia à gravidez, sexualidades desprevenidas e dificuldades em negociar sexo seguro.
\end{abstract}

Palavras-chave: Juventude. Narrativas biográficas. Sexualidades. Gravidez jovem. Instituições de protecção social.

\section{Citizenship, EDUCATION AND SOCIAL RESPONSIBILITY:}

THE BIOGRAPHICAL JOURNEY OF YOUNG PREGNANT WOMEN IN SOCIAL PROTECTION ENVIRONMENTS

ABSTRACT: Sexuality and early pregnancy and childbirth are much debated in the current globalized modernity. Since these complex subjects involve rights, regulation and public social control issues, they are quite relevant in education. Based on the stories of a 17 years old Portuguese and a 19 years old Romanian young women, this paper reveals knowledge. Due to their early pregnancy and motherhood, both live in social protection institutions. The text

\footnotetext{
* Doutora em Ciências da Educação e professora da Faculdade de Psicologia e Ciências da Educação da Universidade do Porto. E-mail: lauradafonseca@hotmail.com

* Mestre em Ciências da Educação e colaboradora do Centro de Investigação e Intervenção Educativas (CIIE) da Universidade do Porto. E-mail: sofiasantos@fpce.up.pt

*** Doutor em Sociologia e professor da Universidade do Porto. E-mail: jcaldas@fpce.up.pt
} 
interprets their speech and subjectivity regarding their experiences before and during guardianship, as well as their projects for the future. The discussion is framed by the relations between the intimate, sexual citizenship and education of each girl. It highlights the social regularities that mark out their lives and that of their child. It also addresses manifestations and regularities related to both gender and power such as: school dropout before pregnancy, unprepared sexuality and difficulties to negotiate safe sex

Key words: Youth. Biographies. Sexualities. Early pregnancy. Social protection institutions.

\section{Citoyenneté, ÉducAtion et Responsabilité Sociale: PARCOURS BIOGRAPHIQUES DE JEUNES FILLES ENCEINTES DANS DES CONTEXTES DE PROTECTION SOCIALE}

RÉSUMÉ: La sexualité, la grossesse et la maternité précoces sont des sujets complexes qui provoquent de vastes débats dans la modernité tardive mondialisée, car ils jouent sur des questions de liberté, de droits, de réglementation et de contrôle social public, constituant donc un important champ éducationnel. Ce texte révèle une connaissance basée sur les narrations d'une Portugaise et d'une Roumaine de 17 et 19 ans qui habitent dans des institutions de protection sociale en raison de leur grossesse et de leur maternité précoces. Il interprète leurs discours et subjectivités quant à leurs vécus avant et pendant leur période de tutelle, mais également en ce qui concerne leurs projets pour le futur. Cette discussion s'inscrit dans le cadre des relations entre citoyenneté sexuelle et intime et éducation dans le parcours de chacune d'entre elles, et elle met en relief les régularités sociales qui traversent leur vie et celle de leur enfant. L'article discute ensuite les manifestations et régularités mettant en jeu des relations entre genre et pouvoir: abandon scolaire préalable à la grossesse, sexualités mal préparées et difficultés à des pratiques sexuelles sans risques, etc.

Mots-clés: Jeunesse. Narrations biographiques. Sexualités. Grossesse précoce. Institutions de protection sociale.

\section{Introdução}

$\mathrm{P}$

ropõe-se neste artigo discutir as experiências e perspectivas de duas jovens, de 17 e 19 anos, uma portuguesa e outra romena, que, por engravidarem, se encontram a residir temporariamente em instituições de protecção social, especificamente numa comunidade de inserção para jovens grávidas e/ou mães, em "situações de risco". ${ }^{1}$ Neste alojamento transitório, espera-se conseguir que as jovens adquiram "competências" e "sentido de responsabilidade", assumindo-se como prioridade a "prevenção e reparação de situações de exclusão ou vulnerabilidade social", através da conjugação de "esforços terapêuticos e educativos" com vista à sua inserção.

A metodologia subjacente a este texto baseia-se na interpretação das duas narrativas biográficas das jovens mães, em busca de: escutar a singularidade dos seus percursos; trazer para o conhecimento científico o carácter heurístico das suas 
narrativas biográficas; e interpretar as experiências e significados atribuídos à sua própria história, segundo o processo de Verstehen (Araújo, 2004). Por sua vez, os discursos e as narrativas resultam de encontros biográficos, realizados num contexto institucional. São, por isso, encontros contextualizados e discursos produzidos enquanto "membros" desse contexto.

As temáticas da pesquisa em causa enquadram-se numa perspectiva de cidadania ampla para a juventude. Juventude é certamente uma categoria atravessada pela diversidade social de grupos e lugares culturais, tal como a cidadania é estendida aos diversos sectores da vida, aqui concretizados mais nas questões da cidadania sexual e intima da juventude feminina transitoriamente sob custódia. Visa-se, assim, a produção de conhecimento educativo sobre percursos e problemáticas actuais da juventude, procurando perceber quem são estas jovens institucionalizadas; a especificidade das suas experiências; os modos como foram e estão a ser educadas e a construir-se como mães e jovens; e as interconexões entre o vivido e os novos contextos e espaços sociais.

\section{Gravidez, maternidade e protecção social}

Neste contexto, a presente reflexão está atravessada por diversas preocupações. Desde logo, a busca de dimensões educativas, na perspectiva de quem as vive. Considera-se que tais dimensões estão dentro e fora das instituições; dizem respeito à experiência passada, presente e desejada; abrangem relações sincrónicas e diacrónicas. Por isso, a interpretação dos discursos das jovens, focalizados tanto na compreensão das dimensões experienciais presentes nos seus percursos anteriores à entrada na instituição, como nos já construídos em contexto de custódia. Deste modo, espera-se contribuir para uma reflexão acerca da natureza educativa do trabalho desenvolvido nestes espaços, muitas vezes situado, na tensão entre trabalho educativo, terapêutico, punitivo e de "reparação". Não se esquece nesta reflexão a tipologia apresentada por Iris Young (1997), que apresenta três modos de acção (punitivo, tratamento ou transformador) com mães toxicodependentes, em que argumenta que os programas que enfatizam tratamento continuam a reter tendências punitivas.

Ainda nesta discussão, realçamos a conceptualização do local-global, no actual contexto de emigração pendular europeia (Kehily, 2009), para interpretar as temáticas das sexualidades, gravidez e parentalidade (Lees, 2000; Walkerdine et al., 2001). Tal aç̧ão permite interligar tanto as especificidades educativas de lugares sociais e institucionais de protecção da infância/juventude, quanto as narrativas das biografadas que abordam o lugar. Nesse contexto, Kehily (2009) argumenta a importância das "novas comunidades de interpretação" como espaços de produção 
de significados, onde instituições e sujeitos, a partir dos consumos jovens, comunicam e constroem novas conversas locais-globais. Por isso, quando escutamos estas jovens, ainda que apresentando-se fortemente ligadas às comunidades, é dada atenção a possíveis influências que certamente atravessam as suas vidas dentro das instituições sociais.

Assim, à luz da cidadania da juventude, estas temáticas podem adquirir outros sentidos e experiências, além das merecidas pela atenção pública. No caso da gravidez, tem sido visibilizada sobretudo a elevada incidência da gravidez adolescente portuguesa, país que ocupa o segundo lugar no contexto europeu (APF, 2004). Perspectivamos essa atenção pública no processo das recentes transformações do equilíbrio entre vida pública e relações de género. Na verdade, a alta taxa de gravidez adolescente acontece ao mesmo tempo que se eleva a idade em que as mulheres têm o primeiro filho e que diminuem as taxas de natalidade, enquanto se espera uma maior participação em percursos educacionais e em carreiras profissionais. A gravidez adolescente quebra as expectativas normatizadas em relação às trajectórias de vida e à fecundidade adequada. Esse é um dos factores que conduz à visão corrente de que gravidez precoce é problema a ser combatido. Todavia, este é um tema com múltiplas mensagens, incluindo a percepção da maternidade como valor positivo de integração das raparigas, em certas comunidades. Além disso, a incidência do fenómeno da gravidez adolescente tem sido focalizada no comportamento problemático feminino, isentando os rapazes e adultos masculinos de responsabilidade, tanto em relação à gravidez e parentalidade, como em relação à saúde sexual e reprodutiva, sobretudo no que toca às doenças sexualmente transmissíveis. Todas estas questões têm certamente implicações profundas nos saberes e nas práticas educativas, nomeadamente de educação sexual.

Também o estudo da sexualidade encontra-se muitas vezes circunscrito ao campo da reprodução, das relações familiares e da heterossexualidade normativa, tendo o debate sido renovado, particularmente a partir dos anos de 1990, quando diversos estudos das ciências sociais passam a explorar o foco da cidadania e justiça social além do âmbito da esfera pública (Arnot et al., 1999; Fonseca, 2009). Estão abertas, assim, novas portas para que os direitos de cidadania se ampliem a questões como a sexualidade e a intimidade, alargando-os a olhares e sujeitos até aqui silenciados e negligenciados nas discussões clássicas (Giddens, 1996). A crítica feminista e dos movimentos gay e lésbico empurraram o debate para a relação entre direitos, género e poder. Propõe-se a extensão dos três direitos de Marshall para incluir um quarto: os direitos culturais. Dessa elaboração emerge o conceito de cidadania sexual, apesar das críticas de hedonismo e individualismo (Richardson \& Turner, 2001). Também Ken Plummer (2003) "rebusca" a noção de "transformação da intimidade" de Giddens e propõe o conceito de cidadania da intimidade de modo a abranger, como esferas de 
direitos de todos/os, a vida privada e as sexualidades. Assim, um número considerável de pesquisas recentes sobre sexualidades consideram cidadania e educação como paradigma heurístico para enfrentar estas questões (Mac an Ghaill, 1994; Holland et al., 1998; Araújo, 2004; Redgrave, 2009; Fonseca, 2009).

Nesse sentido, uma das vantagens de focar gravidez adolescente pelo prisma da cidadania é permitir uma abordagem crítica, promovendo alternativas às leituras centradas em factores psico-biológicos e na falta (informação, recursos, estruturação familiar e emocional...). Este olhar permite perceber o quanto os discursos carencialistas contribuem para o reforço e reprodução da desigualdade social. Cremos que estas aberturas teóricas podem ser um filão para desafiar e reclamar a cidadania da juventude e constituir reflexão importante para melhor compreensão das realidades sociais e educativas vividas e/ou socialmente desejadas para os membros mais jovens da sociedade local e europeia, incluindo a que transitoriamente habita instituições de protecção social, pelo facto de "terem acontecido" gravidez e maternidade jovem.

\section{Percursos cruzados}

\section{0 universo de Dalila}

Dalila nasceu e cresceu na Roménia, numa família trabalhadora. Foi criada com a mãe, a irmã mais nova e o padrasto, a quem chama pai. O seu percurso foi "muito movimentado" nos primeiros anos de escolaridade. Depois do $5^{\underline{o}}$ ao $8^{o}$ ano, ela estabiliza na mesma cidade e escola. Nas perdas e adaptações das movidas, valiam-lhe a presença e cumplicidade da irmã, com quem diz ter aprendido a ultrapassar dificuldades. Também, na adolescência, foi trabalhar para Itália com a sua mãe. De regresso à Roménia, foi encaminhada para uma escola profissional, fora da sua cidade, o que a impediu de frequentar a universidade, como desejava. Na verdade, uma combinação de mudanças e "escolhas" empurram-na a viver numa aldeia, onde tentou vida independente, através do estudo e trabalho.

Já neste novo contexto, estabeleceu um relacionamento longo com um namorado, que, sem comunicar, um dia desapareceu. Ela entrou num processo de distanciamento da escola e decidiu abandoná-la no $10^{\circ}$ ano. Depois, conheceu outro rapaz, com quem se relacionou sexualmente e de quem engravidou, aos 18 anos. A notícia e situação de gravidez são vividas em profunda solidão. Dalila, numa primeira fase, foi tomada pelo medo, vergonha e fama, decidiu não contar a ninguém e tentou "em segredo" para si uma saída, sobretudo porque sabia que o pai do seu filho a abandonou. Foi este novo dado na sua vida que a conduziu a fugir sozinha da Roménia para Portugal. 
A emigração ilegal apareceu-lhe como a possibilidade de fazer face ao problema, longe do escrutínio do local. Acreditava que teria, neste país europeu, a possibilidade de poder ganhar para criar a sua criança. Comprado o bilhete, desembarcou e foi "abandonada" em Lisboa, onde ficou dois dias. Depois, foi conduzida até Faro, onde, cansada e sem saída, se entregou à Segurança Social e daí encaminhada para uma instituição de custódia. Após ser mãe, foi transferida para uma Comunidade de Inserção no Norte, onde reside. É hoje uma jovem mãe, que fala bem a língua portuguesa e cuja vida se limita a cuidar do seu bebé e, em revolta, aguarda ansiosamente o regresso ao país...

\section{0 universo de Daniela}

Daniela nasceu e cresceu no seio de uma família numerosa, composta pela avó, mãe, irmãos, tios, tias, primos, padrasto e filha deste. Com o pai, residente em Espanha, mantinha uma relação de distância devida a excessos de álcool e agressividade. Da relação com a mãe, destacavam-se os conflitos entre ambas, por ter sido obrigada a frequentar a escola e recriminada nas suas "companhias". Todavia, Daniela destacou a influência do grupo de amizade no seu percurso. Esta nasceu na relação conturbada com a escola, marcada pelo absentismo, reprovação e conflitos com seus agentes. A cultura rebelde de grupo em que se inseriu ganhou peso na opção de abandono escolar e entrada no trabalho ou, mesmo, na familiaridade com a condição de mãe. Deixou a escola no $8^{\circ}$ ano e entrou a trabalhar a tempo inteiro num café, onde antes exercia actividade em part-time. Aí foi obrigada a contactar com muitos rapazes e homens, sendo então que conheceu o pai do seu filho. Apesar dos avisos da sua patroa acerca da irresponsabilidade deste com as raparigas, iniciou e manteve este relacionamento. Depois, a pretexto de ciúmes, este pressionou-a ao abandono do trabalho, alegando desacatos e atrevimento dos clientes. Exigência a que Daniela acedeu, ligando-a uma tentativa de violação que sofreu.

Desocupada e dependente, passou a frequentar a casa do namorado, onde "aconteceram" envolvimentos sexuais desprotegidos, porque idilicamente confiava que "ele sabia o que fazia", como lhe afiançava.

Engravidou ao fim de dois meses, situação que desencadeou o abandono do namorado. Em pânico, numa primeira fase, considerou o aborto como opção. Contudo, com o passar do tempo, a ideia de ser mãe nestas circunstâncias começou a ser assimilada. Neste momento, a Segurança Social entrou em cena e, contra a sua vontade, iniciou o processo de institucionalização, por ser considerada uma jovem em risco, onde entrou com 2 meses de gravidez e lá permanece. 


\section{Ser objecto de protecção pública}

\section{Percurso de Dalila}

\section{Turbilhão e pressões: de "mais rapaz" a "rapariga mesmo"}

Dalila, à entrada na juventude, foi confrontada com pressões fortes, no sentido de mudar a feminilidade em que se sentia segura e confortável, para passar a adoptar a versão dominante, considerada mais adequada à nova jovem que deveria emergir:

Não vestia calças apertadas, nem saia, era só fato de treino, cabelo preso e boné. Tinha o cabelo sempre preso, tinha uma trança e prendia o cabelo e andava sempre de chapéu. Era assim mais rapaz.

No seu dizer, o modo como se construíra como rapariga tinha sido estimulado pelo pai e alicerçado na relação com pares da turma, onde existia uma desproporção numérica: 26 rapazes para 6 raparigas. Aî "aprendeu" a lidar com alguns dos dilemas de género, procurando algum poder através de uma maior aproximação e interacção com os rapazes, sem deixar de defender os direitos das raparigas:

Gostava mais de andar com rapazes, eles percebem-me, sei lidar melhor. Agora as raparigas são esquisitas: "ai a minha unha partiu, ai não gosto do meu penteado... Ai aquele rapaz gosta dos meus olhos".

Os dilemas de género empurram, frequentemente, algumas crianças e jovens para construírem uma feminilidade de tipo Maria-Rapaz (Fonseca, 2009). Esta possibilita "realizações respeitáveis" nos seus "circuitos de troca", ao mesmo tempo que as raparigas arriscam ao mínimo a sua segurança, sentindo-se e tornando-se aceites e com algum poder no grupo de pares (Skeggs, 2002, p. 323). Contudo, persistir na juventude neste tipo de feminilidade apresenta riscos e, por isso, Dalila sentia-se "forçada a mudar" e tornar-se "uma jovem adequada". Na verdade, percebeu que, no interior dos cânones da "compulsória" masculinidade hegemónica, que define e escrutina as feminilidades, a sua "transgressão" só foi aceite transitoriamente, porque rasa a fronteira de "mulher adequada". As preferências por companhias e estilos masculinos deviam ser abandonadas. A narrativa de Dalila revela as pressões para assumir "o estilo feminino", o que constitui o processo de entrada na carreira de namoro, onde diversos agentes e instituições intervêm:

A minha mãe, quando cheguei aos 16 anos, já não concordava que andasse sempre com os rapazes... "Já estou farta... a minha menina tem que mudar, não tem que ser sempre 
rapaz". E a minha mãe começou a fazer-me a depilação, as sobrancelhas, a pintar-me... e comecei a gostar.

Com efeito, a pressão que a mãe exerceu para "impor" a mudança a Dalila foi motivo de aplauso e elogio da comunidade, incluindo a escolar, o que revela a natureza genderizada dos sujeitos e instituições sociais:

Toda a gente a olhar para mim dizia: "Vês não tinhas que fazer aquela diferença, rapaz e rapariga. Porque tu és rapariga". Até a professora de música dizia: "Estás esquisita... mas gosto mais de ti assim! A tua mãe já devia ter feito isso há mais tempo...".

Ainda que estas mudanças tenham despertado em Dalila uma atenção e atracção por novos aspectos do mundo masculino, viu-se de repente confrontada na sua intimidade com noções naturalizadas e normatizadas pela moral do corpo adequado como corpo sexy. Estas novas pressões sexy de consumo feminino causaram-lhe constrangimentos e vergonha, sentindo que feriam a sua cidadania sexual e intima:

Quando mudei não gostei muito de mostrar as minhas coisas, a parte de cima do peito, que andava sempre tapada. Não conseguia ver-me bem assim. Estava sempre a tapar, punha um top... um lenço.

Estas são, sem dúvida, questões centrais no processo de se construir e ser construída como rapariga, com pouca segurança, conferindo centralidade à natureza reguladora do trabalho educativo.

\section{Namoro, vergonha e fama: como revelar o desejo?}

Entrar na carreira de namorar exige aprender o saber e o trabalho de se tornar adequada. $\mathrm{O}$ passo que segue nesta carreira do namoro traz consigo dinâmicas de iniciação sexual. Ora, esta dimensão tão central da vida, no caminho do namoro heterossexual, é, muitas vezes, para as raparigas, um palco de confronto de muitas ansiedades, entre aos sentidos de prazer e desejo genuínos que emergem misturados com noções conservadoras dominantes. A narrativa de Dalila nota as dificuldades vividas para negociar interacções sexuais logo com o seu primeiro namorado, com quem iniciou relações sexuais aos 17 anos:

A primeira vez não gostava... as coisas não correram muito bem. Não deixava, não queria, não tomava a pílula. Ele não usava preservativo.... Ainda não estava preparada, comecei cedo de mais, fiquei muito assustada. Comecei a ganhar ódio.

A vergonha constitui marca constante no discurso de Dalila. Uma vergonha sentida, imaginada e mesmo legitimada pelas comunidades. É um sentimento que 
emerge desde cedo na família e se prolonga na vida, o que vai explicar a sua falta de poder para negociar com os parceiros. Na verdade, a ausência de voz para uma adolescente dizer o amor, neste caso a um rapaz, levanta questões sobre o lugar para construir e reclamar cidadania sexual. As relações de género cruzam-se nas experiências vividas que continuam a moldar a vergonha e as interacções sexuais e de namoro. A possibilidade feminina de revelar desejos e afectos íntimos continua a ser considerada alvo de gozo:

E quem passa vergonha? Somos nós...

Tive vergonha quando comecei a ter relações sexuais, porque ainda não estava na altura de ter, era muito pequenina, tinha aquela idade de ser uma rapariga muito frágil. Se vou dizer que comecei a minha relação sexual vão começar a rir-se de mim.

As raparigas correm o risco de "ganhar fama" e ser consideradas sexuais, "tolas" e "atrevidas", o que gera profundas ansiedades e dificulta a prevenção. Então, como revelar e dizer o desejo?

Não achava piada namorar com ele, era muito distante, ficava longe de mim. Eu dizia:

- Estás à espera que eu venha beijar-te?

- Não, eu posso ir.

- Pensava que estava aqui com uma criança.

- Tu és muito atrevida!

\section{3. És a culpada, não devias fazer...}

O modo de fugir a estas marcas é ser "namorada séria". Por isso, Dalila passou a dormir em casa dos pais do namorado. Esta "entrada" ocorreu em contexto de fragilidade, o que é pouco compatível com a autonomia. A solidão que iria experienciar parecia distanciá-la da escola, conferindo ao namorado (e ao trabalho) o centro das suas preocupações.

Também a relação de namoro é vivida com pouca autonomia e poder, o que dá lugar a relações sexuais desprevenidas. Estas acontecem em contexto de vergonha, guiadas por noções de "agradar" e "servir", "aceitando" a dependência, pressões e "enganos" dos parceiros. Isto, sem deixar de pensar que o desejo também está presente, embora nem sempre revelado em condições de poder. Aqui são também lembradas as fantasias românticas veiculadas, face ao uso da contracepção, ficando assim expostas a noções míticas de "acontecer" gravidez e doenças sexualmente transmissíveis (DST). 
As minhas amigas não gostavam do preservativo, "Para que vou tomar isso? Não fico grávida, já fiz tantas vezes e não fiquei". Ainda estão naquela de adolescente. "É mais sensual. É mais lindo sem preservativo.

Os rapazes não gostam de usar.. às vezes enganam a rapariga. Elas não sabem, não têm a noção que ele não tem o preservativo. (...) Às vezes pensamos assim o rapaz não gosta, não se sente confortável. Não pensamos em nós.

Algumas minhas amigas usavam pílula, mas nunca tive ideia de usar. Confiava, "não fico grávida, sou forte"!

A Dalila sabe, por fim, que a responsabilidade da gravidez continua a ser atribuída às mulheres, muitas vezes alvo de chacota:

Se estivesse na Roménia passava grande vergonha por ficar grávida, porque o meu filho estava a crescer dentro da minha barriga... e ele a rir de mim! Mas não é vergonha ficar grávida. É vergonha o que os pais dos filhos fazem. A mãe é que passa vergonha, é que fica sozinha. Eles querem lá saber da vergonha, porque são rapaz e começam a desenrascar-se

Isolamento, abandono e fuga constituíram os modos e recursos de que Dalila dispunha para enfrentar a realidade da gravidez. Por isso, pediu segredo sobre a sua gravidez, tanto ao namorado, como a um amigo a quem contou. Quando a gravidez foi confirmada, o namorado não assumiu a paternidade, culpabilizou-a, humilhou-a e abandonou-a:

- Eu gosto de ti. Mas agora um filho é muita responsabilidade.

- Mas eu não tenho culpa. Tu também tens culpa. Somos os dois culpados.

Ele sempre "Tu és culpada, não devias fazer isso".

- Somos os dois. Naquele dia ninguém usou preservativo.

- Quando soubeste que estavas grávida porque não foste abortar? Sou muito novo... para ter filho.

\section{Emigrar: a solução para a gravidez...}

Dalila decidiu emigrar para Portugal em busca de trabalho e para fugir a tanto infortúnio que a atormentava. A fuga apareceu-lhe como a solução melhor para si:

Sabia, no fundo do meu coração, que ele não ia ficar comigo... que me ia abandonar... O emprego perdia, de certeza... Sabia que não ia ter ninguém do meu lado. Nem dinheiro, nem família, nem casa. Ficava onde?

Tomada pelo impulso e medo de ser "julgada", resolveu comprar um bilhete de autocarro a caminho de Portugal, dizendo à mãe que viria trabalhar com seus 
amigos. Na chegada a Lisboa ficou completamente perdida, confrontando-se com a incomunicabilidade da língua, a ilegalidade, o completo isolamento. Durante quatro dias, circulou entre Lisboa e Faro, num trajecto de sucessivas fugas e enganos que a faziam sentir "estrangeira" e "estranha". Vencida pelo cansaço, fome e sem perspectivas, decidiu entregar-se, abrindo espaço para a entrada do sistema de protecção social, na medida em que lhe foi diagnosticada gravidez, já de sete meses.

\section{Percurso de Daniela: tornar-se objecto de protecção pública}

\section{Desconexão, escola e grupo de pares}

Como vimos, o percurso escolar de Daniela é muito conturbado, irregular e marcado pelo absentismo, reprovação, conflitos com agentes da comunidade escolar. O estatuto rebelde e irreverente que a caracteriza, se, por um lado, explica os insucessos educativos e a insere na categoria de "aluna problemática", por outro, torna-se central para a construção da sua identidade no seio de um grupo de amigas. Assim, o "sentimento de pertença" ao grupo de amizade, igualmente rebelde, dota Daniela de uma feminilidade vista como forte, mas recriminada pelo modo escolar:

Passei para o $8^{\circ}$. Andei e depois comecei a ter problemas e não fui mais... Nós pegávamo-nos com o porteiro da escola... Ele mandava-me para a escola. Comecei a ter problemas... Andávamos à porrada, mal falavam qualquer coisa para nós, a gente era logo "Pimba".

A rede feminina jovem de Daniela evidencia como começa a partilhar um "nós" de "rapariga rebelde", a perturbar e fazer distúrbios. Se, por um lado, fica mais desconectada da escola, por outro, a pertença ao grupo traz algum poder colectivo, frequentemente imposto com agressividade e violência, dirigido a quem questione o estatuto do grupo.

Mas o percurso da Daniela nem sempre foi assim. Ele permite perceber como se produz este processo de se tornar rebelde com algum poder. Na verdade, os seus primeiros tempos escolares são já vividos em desconexão, mas em silêncio e vergonha "dos outros". Sente-se marcada pela sua presença invisível. Então, à medida que se torna jovem, vai negociando a sua inclusão, emergindo de sujeito estranho silencioso a sujeito educacional desconectado, agora visível pela rebelião. Ambas as desconexões são centro e razão para "detestar a escola":

Detestava a escola. Quando entrava, ficava toda a gente a olhar para mim. Não me dava muito com eles... era muito calada, não falava. 
Os quotidianos escolares são marcados por ausência e negação do ensino escolar. Ora, a exploração do "outro lado da escola" aparece como possibilidade rica e gratificante de aprendizagens, especificamente no que diz respeito à construção das suas feminilidades e sexualidades rebeldes e aos modos de afirmação de poderes intra e inter-geracionais. Assim, a orientação por um percurso de distanciamento da vida académica, de absentismo e de "faltas" permite investir na convivialidade rebelde dentro e fora da escola.

Na dependência desta contra-cultura e transgressão colectiva, Daniela realça, no entanto, que gostava de algumas aulas, professores/as. Talvez esta auto-valorização exprima uma vontade de não cortar totalmente os laços com a escola. Porém, as faltas conduzem ao abandono no $8^{\circ}$ ano, juntamente com o seu grupo. A decisão colectiva simboliza não apenas o poder das redes de amizade e resistência femininas, mas também os processos vividos de opressão, que afectam os grupos com poucos recursos, como evidenciam as relações de parentesco existentes:

Para não ser expulsa preferi sair da escola. Saímos para aí 3. Se for a ver a ocupação é quase a mesma, mas só que se a gente a trabalhar ganha dinheiro, enquanto na escola é só escolaridade.

\section{Gravidez, sexualidades desprevenidas}

O poder das redes femininas de amizades na produção de sexualidades e relações rebeldes é fundamental para se contextualizar os percursos das jovens. A gravidez adolescente e a iniciação sexual precoce são questões que encaixam na experiência escolar e do grupo familiar. Embora não desejada pela família, a gravidez é algo que causa pouca estranheza, e pode até ajudar a legitimar o abandono escolar, há muito precedido de desconforto e desconexão, expresso na rebelião do grupo:

Temos sempre imensos casos! As raparigas engravidavam sempre. A minha amiga namora com o meu irmão foi mãe aos 14 anos. Ela queria para sair da escola, porque sabia perfeitamente que se engravidasse, o meu padrasto não a deixava ir.

Ser activa sexualmente surge associada à iniciação sexual do grupo. A "primeira vez" de Daniela aconteceu com o namorado anterior, sexualidade que foi prevenida. Todavia, quando começou a namorar com o pai do filho, houve forte pressão deste para a convencer de que era momento certo. Mais uma vez, a casa dos pais do rapaz continou a ser o "refúgio", onde o par jovem podia legitimamente estar e ter sexo. A Daniela engravidou porque não usavam métodos contraceptivos e porque acreditava romanticamente no namorado, que dizia: "sei o que estou a fazer". 
Apesar da familiaridade com o fenómeno da gravidez jovem, o momento da descoberta foi marcado pela recusa de enfrentamento do "problema". A perspectiva de ser mãe sozinha levantou a questão do aborto.. Mas o tempo foi construindo a aceitação da condição de mãe:

Namorava desde Novembro, em Dezembro engravidei. O meu namorado disse que assumia se estivesse. Em Fevereiro, tive a certeza, contei-lhe e ele deixou-me, mal soube que estava grávida. A partir daí nunca mais quis saber... E eu ao primeiro não queria.. não posso ter... Fiquei!

A desilusão e a tristeza de ter "sido deixada" trouxeram auto-culpabilização por não ter dado ouvidos aos alertas e ter acreditado no namorado. $\mathrm{O}$ ânimo para seguir em frente com a gravidez foi resolvido com a aproximação à mãe, que também estava grávida.

\section{Interpretar experiências em instituições de protecção social}

\section{Experiência de Dalila em duas instituições: "de raparigas" e "de mães"}

Em Portugal há quatro dias, Dalila entregou-se à mulher que lhe perguntou: - "Estás grávida?". A resposta positiva desencadeou os mecanismos de acção do sistema de Segurança Social, sendo colocada numa instituição para raparigas, onde recebeu, logo à entrada, cuidados básicos.

\footnotetext{
“Ela não é portuguesa, é romena, não sabe falar! Entreguem à polícia, expliquem a situação e nós vamos buscá-la".

Eu deixei, desde que ela me ponha num lugar seguro. Foram comigo para uma instituição de protecção de raparigas. Disseram que tinha que tomar banho, vestir roupa limpa, para ir ao hospital porque estava grávida. Tive vergonha de comer à frente daquela técnica. Mas quando ela saiu comi, comi. Estava cheia de fome!

Fizeram um quarto enorme só para mim! Dormi, dormi...

E depois quando me vieram acordar estava cheia de vergonha... muitas raparigas à minha volta... "Ela não sabe falar, é romena, não tentem falar com ela que não percebe nada!".
}

Este espaço de protecção social estranho tornou-se o lugar seguro desejado, sentindo acolhimento e cuidado. Dalila ali permaneceu por dois meses, até ao nascimento do bebé. Ela recorda, com agrado, a ajuda e bem-estar: recursos básicos de saúde, higiene, alimentação e espaço para si; ambiente envolvente de afecto quer de técnicos, quer de pares; estímulo à aprendizagem. Afinal, o cuidado, protagonismo e reconhecimento, ingredientes que a justiça social implica e reclama: 
Cidadania, educação e responsabilidade social: percursos biográficos de jovens grávidas...

Elas puxavam muito por mim para falar. Adorei estar naquela instituição. Aprendi muito.

Foram muito minhas amigas. As técnicas ajudaram-me muito. Fiquei até o Rafael nascer.

Este espaço seguro permitiu a Dalila restabelecer-se e, pelo menos a curto prazo, pensar em si e no seu bebé. Falava e comunicava-se com a família, tentava aproximações e clarificações com o namorado.

Quando nasceu o bebé, Dalila não aceitou a adopção que estava preparada e decidiu pelo regresso ao seu país. Com efeito, foi transferida para a "Comunidade de Inserção" para mães e grávidas jovens, onde foi "acolhida" a fim de se tornar uma boa mãe, enquanto se procedem aos trâmites da repatriação:

Aceitei vir aqui para esta instituição pelo meu filho, porque não quis dar para adopção, queria ficar junto dele. Só vinha por três meses... Acabei por ficar aqui quase dois anos... porque o segurança social não tem dinheiro para me mandar.

A obsessão pelo regresso tomou-a, sobretudo porque tinha uma "vida de espera", de "reclusa", passividade, regulamentos e regras... sob vigilância. Um tempo que nunca mais tem fim...

Quando tive que vir para esta instituição não achei muita piada. Tinham-me dito, "Vais voltar para a Roménia, falta pouco". Tinha que ficar quatro meses. Ao fim de um mês tinham que me fazer uma avaliação para ver como cuidava do meu filho... se sabia cuidar. E vim. Deram-me o regulamento... com muitas regras! Li... Não concordava... Tiraramme o telemóvel... Só temos o telemóvel uma hora das 10-11h da noite. E na Roménia é muito tarde, quando falo com os meus pais. Chorava muito!

Se nos concentrarmos na explicitação de alguns dos ingredientes educacionais da instituição, eles confrontam com experiências interiorizadas de vida de trabalho e formação:

Não posso entrar no curso porque vou embora. Às vezes, fazemos tarefas... Às vezes estamos na cadeira quase a dormir... Às vezes faço o trabalho da casa com materiais, bonecos, carros, carteiras... Quando não tenho mesmo paciência para nada estamos a falar... Eu estou habituada a trabalhar e a estar com os meus amigos... porque aqui não considero ninguém amigo, são colegas... duma instituição.

Nos seus próprios termos, estava a ser apenas tratada e avaliada, num contexto em que sublinhava não haver lugar para afectos e amizades com pares. Sentia-se desesperada, sem perspectivas, revoltada... num quotidiano sem rumo, o que explica a sua agressividade e culpabilidade:

Sou uma pessoa muito agressiva aqui dentro, mesmo se agora neste momento estou a mostrar que estou calma é só para conseguir sair daqui. Estive algumas vezes agressiva com o meu filho, por causa desta instituição. $O$ tribunal não achou piada e mandou-me ficar imenso tempo aqui. Depois há alguns meses atrás fugi desta instituição com o meu 
filho, já não aguentava mais. Queria voltar para a Roménia. Mas, voltei para o Porto... Preciso de autorização para ir. E levei consequências durante dois meses e meio. Nunca fiquei tanto tempo fechada! Perdi a paciência, não conseguia ouvir a criança chorar... Estou-me a sentir muito responsável. Ele está colado a mim. Só penso: já sou uma mãe, tenho de ter mais responsabilidade para mostrar ao meu filho.

A vida de Dalila apresenta um conjunto de tópicos pertinentes para equacionar a complexidade do trabalho sócio-educativo institucional, que serão acrescentados e cruzados com as visões de Daniela.

\section{Experiência institucional de Daniela: "à força, mas ainda bem que estou aqui"}

Apesar da família da Daniela ser alvo de acompanhamento da Segurança Social anterior, devido a vulnerabilidades múltiplas, o seu processo de institucionalização decorre por ausência de condições no contexto familiar para cuidar do bebé. Isto aliado à desresponsabilização e fuga do namorado à paternidade. Ao mesmo tempo, o seu relato evidencia como os múltiplos procedimentos de trabalho e políticas estatais (sociais, educativas e de saúde) parecem ineficazes para lidar com as dinâmicas das sexualidades prevenidas, gravidez, aborto e maternidade presentes:

A minha técnica, antes de vir para cá, esteve a falar comigo. E disse, "mais vale tu abortares e ficares cá". E eu "Não quero". Ela propôs isto. E eu "se for para ir para lá fujo para Espanha ou para a beira do meu pai". A minha técnica apareceu lá de surpresa sem eu saber (...).

Mandou-me para cá porque a minha mãe também estava grávida e não dava jeito ter dois bebés em casa. Ui, passei-me, só vim para cá porque foi lá a Polícia me buscar, senão não vinha.

As tensões e fronteiras entre os modelos de protecção social, judicial e terapêutico de acção estatal para "proteger" os interesses das jovens e crianças legitimam a "reclusão", neste caso tratando a vítima as mães e menores. O desespero de ser "acolhida à força", sem alternativa e poder, expressa a fragilidade deste grupo: "A gente só está cá por causa dos bebés, senão ninguém estava aqui".

Apesar da negação inicial deste processo de internamento forçado, após a fase de acolhimento e adaptação à sua condição de mãe institucionalizada, a Daniela apresenta este contexto como um potencial de mudança na sua vida, porque lhe permite a distância necessária para se proteger de possíveis "asneiras" e "irracionalidades" que poderiam ocorrer, caso continuasse no seu contexto de vida:

Nunca quis vir para aqui, mas... vim. Ainda bem que estou cá. Estava com dois meses e até agora ainda estou com o meu filho. Em casa não tinha condições... Se tivesse lá já tinha feito asneiras... Se visse o pai do meu filho matava-o. A sorte dele é não o apanhar. 
Os quotidianos da instituição são muito regulados em termos de tarefas e horários. Daniela ressalta com negatividade a sua vida, quase circunscrita à educação, higiene e rotinas das práticas de boa mãe. São aprendizagens percepcionadas como importantes como mães, mas que "sabem a pouco" e trazem vidas "paradas" e de pouco cuidado de si:

O meu filho normalmente acorda às $5 \mathrm{~h}$ e não me deixa dormir até às $8 \mathrm{~h}$, depois a gente levanta-se às $6 \mathrm{~h} 45$. Dou-lhe de mamar às $7 \mathrm{~h}$, a partir daí nunca mais dorme, só às $3 \mathrm{~h}$ é que adormece. Mudo-lhe a fralda, dou-lhe de mamar, lavo-lhe a carinha, meto-lhe creme, visto-o, meto-o logo no berçário, para arrumar o meu quarto. Depois tomo o pequeno-almoço às $8 \mathrm{~h} . .$.

Esse controlo alia-se à dificuldade de regulação das relações internas e externas, o que se expressa no reforço dos castigos, da fragmentação dos tempos, na regulação dos contactos com o exterior, como se percebe no caso dos telefonemas:

A princípio havia sempre discussão, a gente levava mais consequências [castigos], agora não. Na sala de convívio só podemos mandar mensagens e não fazer telefonemas. Só usamos o telemóvel uma hora por dia, à noite. Agora, as minhas amigas são daqui da [instituição] porque quando vou lá fora.

Este "enclausuramento" não parece evitar a necessidade que Daniela tem de continuar a manter contacto com o pai do filho que a abandonou. Parece até revelar a dependência e a ilusão de uma possível mudança e "regresso" romântico:

A gente falava por mensagens ou ele ligava-me a saber como é que o menino estava. O meu filho nasceu. Correu bem, foi rápido até. Mandei mensagem ao pai do meu filho. $\mathrm{E}$ ele "então, no fim-de-semana vou vê-lo". Até hoje...

A instituição parece projectar uma intervenção mais centrada na sua condição de mães, pelo que se produz muitas vezes nas jovens um vazio educativo, que dá a sensação de tempo de "espera" e não de viver, como deseja.

Em síntese: a realidade vivida por Dalila e Daniela interrogam seriamente a complexidade e a natureza que envolvem o trabalho social e educativo, legal e terapêutico nestes contextos. Como reconhecer as fronteiras e simultaneidades das raparigas como jovens e como mães?

\section{Considerações finais}

Neste texto debatemos as vidas de duas raparigas que, no mesmo tempo histórico, apesar de nascidas e criadas em pontos tão distantes como a Roménia e Norte de Portugal, se cruzaram na mesma comunidade de inserção. A presença conjunta, na 
mesma geografia espacial e temporal, está relacionada com a universalidade da gravidez adolescente como problema social local/global, do sujeito mulher com poucos recursos. Tal problema deve-se a relacionamentos e sexualidades desprevenidas que ambas enfrentaram e que originaram gravidez e maternidade e, por isso, são alvo de protecção pública como "Outras" vulneráveis/transgressoras. Assim, mais do que conhecer a complexidade do sistema de protecção social e de acolhimento de menores, o primeiro desafio deste trabalho é produzir conhecimento sobre sujeitos protegidos, a partir de e interpretando os seus "vividos" e subjectividades construídas, antes e durante o tempo de institucionalização. Como são vistas e contadas as experiências e as instituições educativas a partir de quem está por dentro? Como é que as jovens sentem e compreendem essas acções de intervenção e "ajuda"? Afinal, elas são a voz e o sentido dos principais sujeitos-mães alvo da intervenção social, educativa e terapêutica.

Em ambos os casos, a gravidez "acontece" e é prosseguida, mesmo tendo sido abandonadas pelos namorados, o que ainda evidencia importantes atravessamentos estruturais de género nos dois contextos, na modernidade tardia. Também, estes percursos são precedidos de desconexão com a escola (e trabalho), sendo investida muita energia feminina para ter/manter namorado. Os relacionamentos sexuais acontecem regularmente em casa das famílias dos seus namorados, enquadrados no "compromisso sério" do namoro. Para as raparigas, esta medida parece conferir segurança e protecção para escapar ao escrutínio de "mulher fácil". Para os rapazes, uma oportunidade suportada, legitimada e fácil de realizar sexo. Neste contexto, as jovens mais facilmente "aceitam" ter sexo, confiando romanticamente, quando os namorados reclamam para si a capacidade de controlar e proteger as relações sexuais. Contudo, em ambas as geografias de feminilidade do século xxı globalizado, se destaca - ainda que com diferentes acentuações, idênticas pressões, vergonhas e conflitos interiores nas relações íntimas - a dificuldade de negociar sexo e prevenção. Isto revela como a variabilidade da reprodução social está expandida e construída nas dinâmicas de poder que os sujeitos experimentam e subjectivam, relacionando consentimento e censura masculina, ao mesmo tempo que feminilidades rebeldes/submissas dispõem de pouco poder.

A transgressão à regulação da sexualidade é denunciada pelo imprevisto da gravidez, cuja visibilidade revela a desadequação, "acusada" inclusivé pelos pais das suas crianças. Esta associação simbólica deixa transparecer relações recriminatórias entre maternidade adolescente e desvio, porque há um desafiar da regra da sexualidade feminina adequada na relação de conjugalidade dominante.

Uma segunda contribuição decorre do olhar sobre a experiência da gravidez e maternidade como motivo de institucionalização. Com efeito, a interpretação realça tanto o sentido protector estatal, como a marca recriminatória de regulação/controlo, sobre a categoria problemática feminina, a precisar de ser tratada/educada. Ora, 
estas jovens, sem deixarem de reconhecer o valor e como a experiência institucional se tornou segura e importante nas suas vidas, também exprimem este conflito vivido contraditório da maternidade como "único" centro de preocupação e acção institucional. A interpretação das suas histórias e percursos, quando cruzados com a experiência institucional, coloca na agenda dimensões educativas importantes para desafiar estas organizações como lugar seguro e de bem-estar. Desde logo, a satisfação das condições de vida básicas; proteç̧ão a possíveis "desvios"; criação de espaços para estar consigo próprias - cidadania íntima; acesso a redes e ambientes sensitivos; existência de alguns dispositivos de aprendizagem; benefício de ajuda e mediação.

Estas peças institucionais conjugam hoje dinâmicas e proximidades de percursos locais-globais. As culturas institucionais confrontam-se com multiculturalidade de experiências, sujeitos e noções sócio-antopológicas, produzindo-se "comunidades interpretativas" e novas abordagens educativas e de cidadania. Todas estas questões têm certamente implicações profundas nos saberes e práticas sócio-educativas para enfrentar a universalidade da problemática da gravidez e maternidade entre jovens.

\section{Nota}

1. Sob tutela da Segurança Social, ao abrigo da Lei de Protecção de Crianças e Jovens em Perigo (LPCJP, 1999).

\section{Referências}

APF. Mamãs de palmo e meio: gravidez e maternidade na adolescência. Lisboa: APF, 2004.

ARNOT, M.; DAVID, M.; WEINER, G. Closing the gender gap. Oxford: Polity, 1999.

ARAÚJO, H. Em torno das subjectividades e de Verstehen em histórias de vida de professoras primárias nas primeiras décadas do século xx. In: AвRAHão, H. (Org.). A aventura (auto) biográfica: teoria e empiria. Porto Alegre: EDIPUCRs, 2004. p. 311-327.

FONSECA, L. Justiça social e educação: vozes, silêncios e ruídos na escolarização das raparigas ciganas e paya. Porto: Afrontamento, 2009.

GIDDENS, A. Transformações da intimidade: sexualidade, amor e erotismo nas sociedades modernas. Oeiras: Celta, 1996.

HOLLAND, J. et al. The male in the head: young people, heterosexuality and power. London: Tufnell, 1998 
KEHILY, J.; NAYAK, A. Global femininities: consumption, culture and the significance of plac. In: Dillabough, J. et al. (Ed.). Troubling gender in education. London: Routledge, 2009. p. 24-41.

LEES, S. Sexuality and citizenship education. In: Arnot, M.; Dillabough, J. (Org.). Challenging democracy: international perspectives on gender, education and citizenship. London; New York: Routledge; Falmer, 2000. p. 259-277.

MAC AN GHAILL, M. The making of men: masculinities, sexualities and schooling. Buckingham: Open University, 1994.

PLUMMER, K. Intimate citizenship and the cultural of sexual story telling. In: WEEKS, J. et al. (Ed.). Sexualities and society. Cambridge: Polity, 2003. p. 33-41.

REDGRAVE, K. Intimate citizenship?: tackling gender and cultural issues in community sexual health education. 2009. 320f. Tese (Doutorado) - Faculdade de Psicologia e de Ciências da Educação, Universidade do Porto, Porto.

RICHARDSON, E.; TURNER, B. Review article: sexual, intimate or reproductive citizenship. Citizenship Studies, Abingdon, v. 5, n. 3, p. 329-338, 2001.

SKEGGS, B. Ambivalent feminilities. In: Jackson, S.; Scotт, S. (Ed.). Gender a sociological reader. London: Routledge, 2002. p. 311-325.

WALKERDINE, V. et al. Growing up girl: psychosocial explorations of gender and class. London: Palgrave, 2001.

YOUNG, I. Intersecting voices: dilemmas of gender, political philosophy and policy. Princeton: Princeton University, 1997.

Recebido em 20 de fevereiro de 2010.

Aprovado em 16 de dezembro de 2010. 